\title{
ESTIMATES OF CROSSBREEDING PARAMETERS FOR GROWTH AND CONFORMATION TRAITS IN NIGERIAN INDIGENOUS AND EXOTIC PIG BREEDS
}

\author{
OKORO, V. M. O.* MBAJIORGU, C. A. \\ Department of Agriculture and Animal Health, University of South Africa \\ Florida 1710, Republic of South Africa \\ *Corresponding author \\ e-mail:melavicong@gmail.com \\ (phone: +27-116-709-788; +27-728-720-460) \\ (Received $2^{\text {nd }}$ Feb 2017; accepted $18^{\text {th }}$ May 2017)
}

\begin{abstract}
Information on the crossbreeding parameter estimates involving Nigerian Indigenous pigs and exotic breeds are rare, as well as the best combination for improved growth and conformation traits. A $3 \times 3$ diallel cross was conducted among three breeds of pigs - Large White (WW), Landrace (RR) and Nigerian Indigenous pig (NN) breeds. Growth traits measured were body weight at birth (BWB), weaning (BWW at 6 weeks), maturity of 20 weeks (BW20) and average daily gain (ADG up to 20 weeks), while conformation traits were heart girth (HG), height-at-withers (HW), and body length (BL) all at 20 weeks of age. Significant heterotic and maternal effects were reported for BWW, BW20 and ADG. Also significant specific heterosis was recorded only for BW20, with no significant reciprocal effect for the other growth traits measured. Significant heterotic effects for HG and BL were also recorded, while maternal effect was significant only for BL. Significant specific heterosis was recorded for HG, while reciprocal effect was significant only for $\mathrm{HW}$ and $\mathrm{B}$. This implies that for growth traits, RR, WW and NN breeds had the best combining ability for BWW, BW20 and ADG respectively with a high positive average heterosis of $0.06,2.53$ and 1.58 . This shows that $\mathrm{NN}$ breed could elicit attractive economic and environmental benefits when crossbred with exotic ones, in terms of growth traits, as shown by the significant crossbreeding parameter values reported.
\end{abstract}

Keywords: diallel cross, heterosis, maternal effect, reciprocal effects, pig production

\section{Introduction}

Various attempts had been made to improve pig strains by identifying the best combining ability in terms of heterosis, maternal and reciprocal effects using diallel cross (Fernandez et al., 2002; Garcia-Casco et al., 2012; Ibanez-Escriche et al., 2014). The main purpose of crossing is to produce superior crosses to improve fitness, conformation and fertility traits, and to combine different characteristics in which the crossbreds were valuable (Balaguer, 2014). Improvement of different traits in pigs have been attempted using cross breeding estimates; such as carcass characteristics (Sutha et al., 2015), semen qualities (Gonzalez-Pena et al., 2015), reproduction and growth traits (Hsu and Johnson, 2014), fat deposition and fatty acid profiles (Ibanez-Escriche et al., 2016). The estimation of crossbreeding effects (direct genetic effect, heterotic effect, maternal effect and reciprocal effect, combining ability - General (GCA) and Specific (SCA)) therefore are of major importance. The testing of populations to attain evaluation of their combining ability requires systematic crossbreeding design. The diallel crossing is one such design. A diallel cross is a set of possible combinations between lines, breeds or general populations (Jakubec et al., 1987). Desirable characteristics of different breeds can be utilized if some breeds can be identified as good maternal breeds and others as good paternal breeds. 
There is dearth of information on the crossbreeding effects of Nigerian indigenous pigs with exotic ones, particularly on estimates of crossbreeding parameters in such mating scheme. Duro et al. (2015) attempted the use of diallel cross method involving Nigerian indigenous pig and two exotic breeds to evaluate the effects of cross, parity and sex on bodyweight and morphometric traits among them and these estimates lacked information on crossbreeding parameters. This study is, therefore, aimed at estimating the crossbreeding parameters on growth and conformation traits in a complete diallel cross involving Nigerian indigenous, Large white and Landrace breeds, which are used mainly for production in Nigeria.

\section{Materials and Methods}

\section{Study location}

This research was carried out at the piggery unit of the Teaching and Research Farm of the Federal University of Technology Owerri, Imo State Nigeria between 2009 and 2014. The facility lies between Latitudes $4^{0} 04^{\prime}$ and $6^{\circ} 03^{\prime} \mathrm{N}$ and Longitudes $6^{0} 15^{\prime}$ and $8^{0} 15^{\prime} \mathrm{W}$. The mean annual rainfall is $2500 \mathrm{~mm}$, temperature ranges from 26.5 to $27.5^{0}$ $\mathrm{C}$, and humidity ranges from 70 to $80 \%$.

\section{Animals and experimental design}

A complete $3 \times 3$ diallel cross involving three breeds of pigs, namely Large White (WW), Landrace (RR) and Nigerian Indigenous pig (NN) breeds was conducted. The resultant possible mating combinations included 3 purebreds (WW, RR and NN) and 6 crossbreds (WR, WN, RW, RN, NW, and NR). The base population includes 5 sires per breed and 10 dams per breed which resulted in a total of 148 offsprings farrowed (Table 1).

Table 1. Mean ( \pm SEM) for the some growth traits measured

\begin{tabular}{lcccc}
\hline & \multirow{2}{*}{$\begin{array}{c}\text { Number from } \\
\text { brosses }\end{array}$} & \multicolumn{3}{c}{ Mean traits ${ }^{1} \pm$ SEM } \\
\cline { 4 - 5 } & birth- weaning & BWB $(\mathrm{kg})$ & BWW $(\mathrm{kg})$ & ADG $(\mathrm{g})$ \\
\hline $\mathrm{W} \times \mathrm{W}$ & 25 & $1.42 \pm 0.06$ & $7.25 \pm 0.36$ & $138.81 \pm 28.74$ \\
$\mathrm{R} \times \mathrm{R}$ & 24 & $1.53 \pm 0.07$ & $7.37 \pm 0.30$ & $140.05 \pm 27.62$ \\
$\mathrm{~N} \times \mathrm{N}$ & 21 & $0.92 \pm 0.03$ & $5.36 \pm 0.15$ & $105.71 \pm 18.07$ \\
$\mathrm{~W} \times \mathrm{R}$ & 17 & $1.22 \pm 0.04$ & $7.51 \pm 0.34$ & $149.76 \pm 16.76$ \\
$\mathrm{~W} \times \mathrm{N}$ & 13 & $0.82 \pm 0.07$ & $5.94 \pm 0.46$ & $121.90 \pm 19.72$ \\
$\mathrm{R} \times \mathrm{W}$ & 15 & $1.10 \pm 0.04$ & $6.25 \pm 0.33$ & $122.61 \pm 27.51$ \\
$\mathrm{R} \times \mathrm{N}$ & 12 & $1.02 \pm 0.04$ & $7.12 \pm 0.29$ & $145.24 \pm 23.05$ \\
$\mathrm{~N} \times \mathrm{W}$ & 10 & $1.01 \pm 0.05$ & $6.85 \pm 0.39$ & $139.05 \pm 18.43$ \\
$\mathrm{~N} \times \mathrm{R}$ & 11 & $0.94 \pm 0.03$ & $6.66 \pm 0.34$ & $136.19 \pm 22.91$ \\
$\mathrm{Parity}{ }^{3}$ & & & & $129.52 \pm 18.75$ \\
1 & 65 & $1.18 \pm 0.04$ & $6.62 \pm 0.20$ & $135.02 \pm 22.15$ \\
2 & 83 & $1.15 \pm 0.03$ & $6.82 \pm 0.16$ & $130.24 \pm 19.75$ \\
$\mathrm{Sex}{ }^{4}$ & & & & $135.50 \pm 27.09$ \\
1 & 73 & $1.13 \pm 0.04$ & $6.60 \pm 0.18$ & \\
2 & 75 & $1.20 \pm 0.04$ & $6.87 \pm 0.17$ & \\
$\mathrm{TOTAL}$ & 148 & & & \\
\hline
\end{tabular}

${ }^{1} \mathrm{BWB}=$ Bodyweight at birth, $\mathrm{BWW}=$ Bodyweight at 6 weeks weaning, $\mathrm{ADG}=$ Average daily gain upto 20 weeks, $\mathrm{SEM}=$ Standard error of mean.

${ }^{2}$ Breed of boar $x$ Breed of sow, $\mathrm{W}=$ Large White, $\mathrm{R}=$ Landrace, $\mathrm{N}=$ Nigerian Indigenous.

${ }^{3}$ Parity $1=$ first parity, Parity $2=$ second parity.

${ }^{4} \operatorname{Sex} 1=$ Female, Sex $2=$ Male. 
The method of identification was through the use of ear notching identical for each pure bred and cross bred genetic groups. The initial crossbred population was generated between 2009 and 2011 (Okoro, 2012), while the pure population was generated between 2011 and 2014. The data used were records from 2 parities per cross in the experiment from the population bred at the Teaching and Research farm. The number of records, cross distribution and the summary statistics for all the traits measured are shown in Tables 1 and 2.

Table 2. Mean $( \pm S E M)$ for a growth and conformation traits measured

\begin{tabular}{lrrlll}
\hline & Number & at & \multicolumn{5}{c}{ Mean traits ${ }^{1} \pm$ SEM } \\
\cline { 3 - 6 } maturity & & BW20 $(\mathrm{kg})$ & HG $(\mathrm{cm})$ & HW $(\mathrm{cm})$ & BL $(\mathrm{cm})$ \\
\hline $\mathrm{W} \times \mathrm{W}$ & 24 & $57.22 \pm 1.54$ & $52.88 \pm 2.08$ & $48.65 \pm 1.65$ & $65.71 \pm 1.85$ \\
$\mathrm{R} \times \mathrm{R}$ & 23 & $58.26 \pm 1.80$ & $50.13 \pm 1.47$ & $48.35 \pm 1.63$ & $70.26 \pm 1.47$ \\
$\mathrm{~N} \times \mathrm{N}$ & 20 & $42.48 \pm 0.97$ & $46.55 \pm 1.09$ & $41.80 \pm 1.08$ & $60.80 \pm 0.94$ \\
$\mathrm{~W} \times \mathrm{R}$ & 15 & $50.67 \pm 1.35$ & $50.00 \pm 1.53$ & $47.40 \pm 0.99$ & $62.60 \pm 1.03$ \\
$\mathrm{~W} \times \mathrm{N}$ & 12 & $44.52 \pm 1.32$ & $46.75 \pm 1.38$ & $45.70 \pm 1.15$ & $57.17 \pm 1.75$ \\
$\mathrm{R} \times \mathrm{W}$ & 14 & $52.53 \pm 1.14$ & $53.22 \pm 0.92$ & $48.74 \pm 0.93$ & $72.29 \pm 0.91$ \\
$\mathrm{R} \times \mathrm{N}$ & 11 & $52.76 \pm 0.98$ & $52.86 \pm 1.05$ & $51.03 \pm 0.86$ & $71.86 \pm 1.48$ \\
$\mathrm{~N} \times \mathrm{W}$ & 9 & $46.68 \pm 1.14$ & $48.33 \pm 2.07$ & $47.61 \pm 1.99$ & $64.44 \pm 2.63$ \\
$\mathrm{~N} \times \mathrm{R}$ & 11 & $46.15 \pm 0.95$ & $48.36 \pm 1.52$ & $45.68 \pm 1.55$ & $70.36 \pm 1.42$ \\
$\mathrm{Parity}$ & & & & & \\
1 & 62 & $51.45 \pm 1.12$ & $49.18 \pm 0.94$ & $47.09 \pm 0.85$ & $65.87 \pm 1.09$ \\
2 & 77 & $50.79 \pm 0.86$ & $50.76 \pm 0.71$ & $47.14 \pm 0.67$ & $66.32 \pm 0.81$ \\
$\mathrm{Sex}{ }^{4}$ & & & & & \\
1 & 67 & $50.19 \pm 1.00$ & $49.97 \pm 0.83$ & $46.48 \pm 0.82$ & $65.85 \pm 0.92$ \\
2 & 72 & $51.91 \pm 0.94$ & $50.13 \pm 0.80$ & $47.72 \pm 0.67$ & $66.37 \pm 0.94$ \\
TOTAL & 139 & & & & \\
\hline
\end{tabular}

${ }^{1} \mathrm{BW} 20=$ Bodyweight at 20 weeks maturity, $\mathrm{HG}=$ Heart girth at 20 weeks, $\mathrm{HW}=$ Height at withers at 20 weeks, $\mathrm{BL}=$ Body length at 20 weeks, $\mathrm{SEM}=$ Standard error of mean.

${ }^{2}$ Breed of boar $x$ Breed of sow, $\mathrm{W}=$ Large White, $\mathrm{R}=$ Landrace, $\mathrm{N}=$ Nigerian Indigenous.

${ }^{3}$ Parity $1=$ first parity, Parity $2=$ second parity.

${ }^{4}$ Sex $1=$ Female, Sex 2 = Male.

\section{Management of experimental animals}

The parent animals were fed ad libitum on concentrates containing $17 \%$ crude protein $(\mathrm{CP})$ and $2,480 \mathrm{Kcal} / \mathrm{kg}$ energy. A concentrate feed containing $24 \% \mathrm{CP}$ and $2,500 \mathrm{Kcal} / \mathrm{kg}$ energy was also used to flush the sows during the gestation period to enhance nutrients for embryonic and foetal development. Other management practices of animals in the study are in accordance with descriptions in study by (Duro et al., 2015).

\section{Parameters measured}

The parameters measured were growth traits and conformation traits taken from the purebreds and the crossbred progenies at the various stages of growth which includes:

1) Growth traits

i) Birth weight taken at birth of the piglets using $50 \mathrm{~kg}$ weighing scale ${ }^{\circledR}$ Salter England);

ii) Weaning weight taken at 6 weeks after birth using 200kg bridge weighing scale ( ) Global Universal, England); 
iii) Maturity weight taken at 20 weeks post birth using $200 \mathrm{~kg}$ bridge weighing scale ( Global Universal, England);

iv) Average Daily gain taken daily as the difference between initial weight and current weight taken from birth to maturity at 20 weeks.

2) The conformation traits taken at 20 weeks post birth which includes:

i) Heart Girth (HG): Measured as the circumference of the animal body taken immediately posterior to the shoulder, using a tailor's tape;

ii) Height at Withers (HW): Measured as the distance from the highest point on the dorsum of the animal to the ground surface, at the level of the front feet, using a tailor's tape;

iii) Body length (BL): Measured as the distance from the point of the scapular to the pin bone of the tail base, using a tailor's tape.

\section{Statistical analysis}

The following statistical model according to (Jakubec et al., 1987) was used to analyse the diallel cross:

$$
y_{h i j k}=\mu^{B}+a_{h}^{B}+p_{l i i}^{B}+g_{2 i}^{B}+g_{2 j}^{B}+c_{2 i j}^{B}+m_{2 j}^{B}+r_{2 i j}^{B}+e_{i j k}^{B}
$$

Where

$y_{\text {hijk }}=$ the $\mathrm{k}$-th observation on the progeny of a mating of a dam from the $\mathrm{j}$-th line with a sire of the $\mathrm{i}$-th line in the $\mathrm{h}$-th type of breeding (purebred or crossbred, $\mathrm{h}=1,2$ ), $\mu^{B}=$ mean of the purebred and crossbreds, $a_{h}^{B}=$ effects common to all progeny of the hth type of breeding (purebred or crossbreds); similar to average heterosis $\left(\bar{h}^{A}\right)$ in model A (Eisen et al., 1983), $p_{\text {lii }}^{B}=$ effect common to all progeny of a mating between a dam of the i-th line and a sire of the i-th line; $g_{2 i}^{B}=$ general combining ability of the i-th line, $c_{2 i j}^{B}=$ specific combining ability of the ij-th line cross, $m_{2 j}^{B}=$ maternal genetic effect of the $\mathrm{j}$-th line, $r_{2 i j}^{B}=$ residual reciprocal effect in the cross $\mathrm{ij}, e_{i j k}^{B}=$ random error. The subscript 1 denotes that the effects are measured only among the purebred progeny, while the subscript 2 denotes that the effects are measured only among the crossbred progeny.

Restrictions imposed on the parameter estimates are:

$$
\begin{aligned}
& \sum_{h} a_{h}^{B}=\sum_{i} p \quad{ }_{l i i}^{B}=\sum_{i} g \quad{ }_{2 i}^{B}=\sum_{j} m \quad \underset{2 j}{B}=\sum_{i} c \quad \quad \underset{2 i j}{B}=\sum_{j} c \quad \underset{2 j i}{B}=\sum_{i} r \quad \underset{2 i j}{B}=\sum_{j} r_{2 j i}^{B} \\
& =r_{2 i j}^{B}+r_{2 j i}^{B}=0
\end{aligned}
$$

The least squares estimators of the parameters are as shown in (Jakubec et al., 1987), where model A is the model developed by (Eisen et al., 1983) while model B is developed by (Harvey, 1960) and extended by (Jakubec et al., 1987). The choice of this model (Model B) is because it is the most appropriate when the parental lines are less than 4. With all the crossbreeding parameters being the major interest in this study, relating some aspects of model A to model B according to (Jakubec et al., 1987) was necessary in order to capture all the parameters of heterosis (direct, line and specific heterosis) and maternal effects (direct and maternal genetic effects). The equations that relate parameters in model A to model B are as shown below: 


$$
\begin{gathered}
\bar{\mu}^{B}=\bar{\mu}^{A}+1 / 2 \bar{h}^{A} \\
\bar{a}_{1}^{B}=-1 / 2 \bar{h}^{A} \\
\bar{a}_{2}^{B}=1 / 2 \bar{h}^{A} \\
\bar{p}_{l i i}^{B}=\bar{v}_{i}^{A}+\bar{m}_{i}^{A} \\
\bar{g}_{2 i}^{B}=1 / 2 \bar{v}_{i}^{A}+\bar{h}_{i}^{A} \\
\bar{c}_{2 i j}^{B}=\bar{s}_{i j}^{A} \\
\bar{m}_{2 j}^{B}=\bar{m}_{j}^{A} \\
\bar{r}_{i j}^{B}=\bar{r}_{i j}^{A}
\end{gathered}
$$

The simple difference in the two models is in the estimation of the direct genetic effect and line heterosis in model $\mathrm{A}$ which are substituted with the term general combining ability in model B. The model A parameters for heterosis $\bar{h}^{A}$ and $\bar{h}_{i}^{A}$ were derived from model B parameters according to (Jakubec et al., 1987) thus;

$$
\bar{h}^{A}=\bar{a}_{2}^{B}-\bar{a}_{1}^{B} \text { or } \bar{h}^{A}=2 \bar{a}_{2}^{B} \text { and } \bar{h}_{i}^{A}=\bar{g}_{2 i}^{B}-\frac{\bar{p}_{l i i}^{B}-\bar{m}_{2 i}^{B}}{2}
$$

Therefore, heterosis and maternal effects were estimated from these expressions based on the number of parental lines, which is three, leading to all the parameters for heterosis captured. Where there were significant least squares estimate, the least significant difference (LSD) method was used to separate the means (SAS Institute, 2010).

\section{Results}

There were significant effects due to direct and maternal genetic effects, GCA, line heterosis and maternal effects on growth traits as estimated from equations 7, 8 and 9 , at a probability levels of $95 \%$ and $99 \%(\mathrm{P}<0.05$ and $\mathrm{P}<0.01)$ (Table 3). However, significant specific heterosis was reported only for BW20 $(\mathrm{P}<0.01)$, and no significant reciprocal effect was reported for all the growth traits measured. The significant GCA translates to significant line heterosis on three growth traits measured viz BWW, BW20 and ADG up to 20 weeks (Table 3).

However, the values of crossbreeding parameters for the Large White genotype consistently expressed positive values for the growth traits, particularly at weaning, maturity and ADG, except for heterosis and maternal effects which expressed negative values (Figs. 1B, 1C, 1D, $1 E \& 1 F$ ). 
Table 3. Least squares means and standard errors of crossbreeding parameter (Overall mean - $\mu$, mean heterosis - $h$, direct \& maternal genetic effects - $p$, general combining ability $g$, line heterosis - $h$, maternal effects - $m$, specific heterosis - $c$ and reciprocal effects - r)for growth traits

\begin{tabular}{|c|c|c|c|c|c|c|c|c|}
\hline \multirow[b]{2}{*}{ Parameters } & \multicolumn{2}{|c|}{ BWB (kg) 0days } & \multicolumn{2}{|c|}{ BWW(kg) 42days } & \multicolumn{2}{|c|}{ BW20 (kg) } & \multicolumn{2}{|c|}{$\mathrm{ADG}(\mathrm{g})$} \\
\hline & Mean & SEM & Mean & SEM & Mean & SEM & Mean & SEM \\
\hline$\mu$ & 1.16 & 0.49 & 6.69 & 2.24 & 49.19 & 16.03 & 132.78 & 20.78 \\
\hline $\mathrm{h}$ & -0.27 & 0.11 & 0.06 & 0.02 & 2.53 & 1.03 & 1.58 & 0.03 \\
\hline $\mathrm{a}_{1}{ }^{\#}$ & 0.14 & 0.06 & -0.03 & 0.01 & -1.27 & 0.02 & -0.79 & 0.02 \\
\hline $\mathrm{a}_{2}^{\# 1}$ & -0.14 & 0.05 & 0.03 & 0.01 & 1.27 & 0.015 & 0.79 & 0.015 \\
\hline $\mathrm{p}_{\mathrm{Ww}}$ & 0.13 & 0.02 & $0.59^{\mathrm{a}}$ & 0.26 & $2.43^{\mathrm{a}}$ & 0.24 & $3.94^{b}$ & 0.57 \\
\hline $\mathrm{p}_{\mathrm{RR}}$ & 0.24 & 0.07 & $0.71^{\mathrm{a}}$ & 0.29 & $3.00^{\mathrm{a}}$ & 0.23 & $-0.77^{\mathrm{c}}$ & 0.56 \\
\hline $\mathrm{p}_{\mathrm{NN}}$ & -0.37 & 0.11 & $-1.01^{b}$ & 0.39 & $-8.42^{\mathrm{b}}$ & 0.83 & $8.57^{\mathrm{a}}$ & 3.56 \\
\hline Sig. & ns & & $*$ & & $* *$ & & $*$ & \\
\hline $\mathrm{g}_{\mathrm{W}}$ & 0.01 & 0.02 & $0.14^{\mathrm{b}}$ & 0.24 & $1.69^{\mathrm{a}}$ & 0.56 & $1.13^{b}$ & 0.79 \\
\hline $\mathrm{g}_{\mathrm{R}}$ & 0.16 & 0.05 & $0.44^{\mathrm{a}}$ & 0.16 & $-3.53^{b}$ & 3.08 & $-4.23^{c}$ & 4.20 \\
\hline $\mathrm{g}_{\mathrm{N}}$ & -0.20 & 0.06 & $0.17^{b}$ & 0.47 & $-5.78^{\mathrm{b}}$ & 1.94 & $2.54^{\mathrm{a}}$ & 0.87 \\
\hline Sig. & ns & & $*$ & & $*$ & & $*$ & \\
\hline $\mathrm{h}_{\mathrm{W}}$ & -0.04 & 0.02 & $-0.22^{b}$ & 0.13 & $0.58^{\mathrm{a}}$ & 0.24 & $0.05^{b}$ & 0.02 \\
\hline$h_{R}$ & 0.03 & 0.017 & $0.215^{\mathrm{a}}$ & 0.09 & $-5.88^{b}$ & 2.40 & $0.18^{\mathrm{a}}$ & 0.05 \\
\hline $\mathrm{h}_{\mathrm{N}}$ & 0.03 & 0.02 & $0.74^{\mathrm{a}}$ & 0.30 & $-2.32^{\mathrm{b}}$ & 0.94 & $0.11^{b}$ & 0.08 \\
\hline Sig. & ns & & $*$ & & $* *$ & & $*$ & \\
\hline $\mathrm{m}_{\mathrm{W}}$ & 0.03 & 0.01 & $-0.12^{b}$ & 0.05 & $0.22^{\mathrm{a}}$ & 0.09 & $0.92^{b}$ & 0.08 \\
\hline $\mathrm{m}_{\mathrm{R}}$ & 0.01 & 0.004 & $0.27^{\mathrm{a}}$ & 0.16 & $-1.71^{b}$ & 0.70 & $0.77^{\mathrm{b}}$ & 0.12 \\
\hline $\mathrm{m}_{\mathrm{N}}$ & -0.04 & 0.02 & $-0.15^{b}$ & 0.06 & $-1.49^{b}$ & 0.61 & $1.75^{\mathrm{a}}$ & 1.54 \\
\hline Sig. & ns & & $*$ & & $*$ & & $*$ & \\
\hline $\mathrm{c}_{\mathrm{WR}}$ & -0.04 & 0.013 & 0.50 & 0.17 & $8.41^{\mathrm{a}}$ & 2.80 & 0.82 & 0.15 \\
\hline$c_{\mathrm{WN}}$ & 0.08 & 0.026 & -0.49 & 0.16 & $-1.62-$ & 0.54 & -1.85 & 1.47 \\
\hline$c_{\mathrm{RN}}$ & 0.02 & 0.007 & 0.49 & 0.16 & $8.41^{\mathrm{a}}$ & 2.79 & 1.86 & 1.06 \\
\hline Sig. & ns & & ns & & $* *$ & & ns & \\
\hline $\mathrm{r}_{\mathrm{WR}}$ & 0.02 & 0.006 & 0.33 & 0.10 & -0.24 & 0.07 & 0.53 & 0.08 \\
\hline$r_{W N}$ & -0.26 & 0.075 & 0.09 & 0.03 & -4.5 & 1.30 & 0.79 & 0.18 \\
\hline $\mathrm{r}_{\mathrm{RN}}$ & 0.04 & 0.02 & 0.22 & 0.06 & -0.22 & 0.06 & 1.35 & 1.33 \\
\hline Sig. & ns & & ns & & ns & & ns & \\
\hline
\end{tabular}

${ }^{\#}$ and $^{\# 1}=$ purebred and crossbred heterosis respectively. ${ }^{\mathrm{abc}}$ means on the same column within the same parameter but with different superscripts are significantly different. $*=\mathrm{P}>0.05, * *=\mathrm{P}>0.01$.

For the conformation traits, there were significant direct and maternal genetic effects on $\mathrm{HG}$ and $\mathrm{HW}(\mathrm{P}<0.05)$ but none on $\mathrm{BL}(\mathrm{P}>0.05)$. GCA was significant on $\mathrm{HG}(\mathrm{P}<$ $0.01)$ and $\mathrm{BL}(\mathrm{P}<0.05)$, resulting in a significant line heterosis on the two traits respectively but none significant on HW (Table 4). These are based on equations 7 to 11. Meanwhile, maternal effects and specific heterosis were significant on BL $(\mathrm{P}<$ $0.05)$ and $\mathrm{HG}(\mathrm{P}<0.01)$ respectively, while reciprocal effects were significant on HW $(\mathrm{P}<0.05)$ and $\mathrm{BL}(\mathrm{P}<0.01)$ traits, respectively. The conformation traits also showed an inconsistent distribution of values for the crossbreeding parameters measured. Apart from heterosis, GCA and reciprocal effects in the Large White genotype reflected negative values throughout the period of the experiment, while the rest were all positive estimates of crossbreeding parameters (Figs. $2 A, 2 B, 2 C, 2 D, 2 E \& 2 F$ ). 

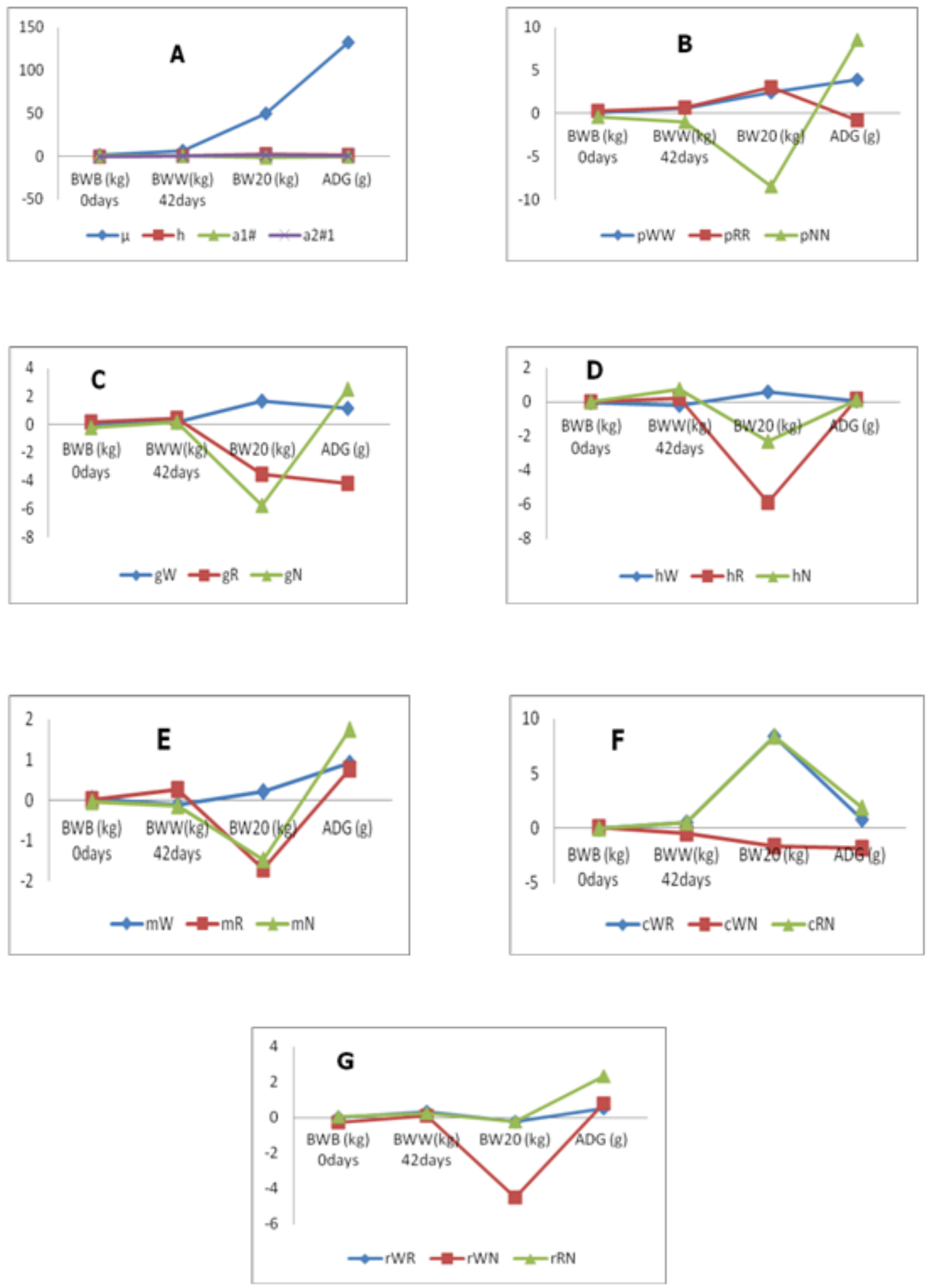

Figure 1. Interactive graph showing the estimates of crossbreeding parameters for growth traits (body weight at birth $-B W B$, bodyweight at weaning $-B W W$, body weight at maturity of 20 weeks $-B W 20$, \& average daily gain up to 20 weeks $-A D G) ; \mu=$ Overall mean, $h(A)=$ mean heterosis, $p=$ direct \& maternal genetic effects, $g=$ general combining ability, $h(D)=$ line heterosis, $m=$ maternal effects, $c=$ specific heterosis, and $r=$ reciprocal effects 

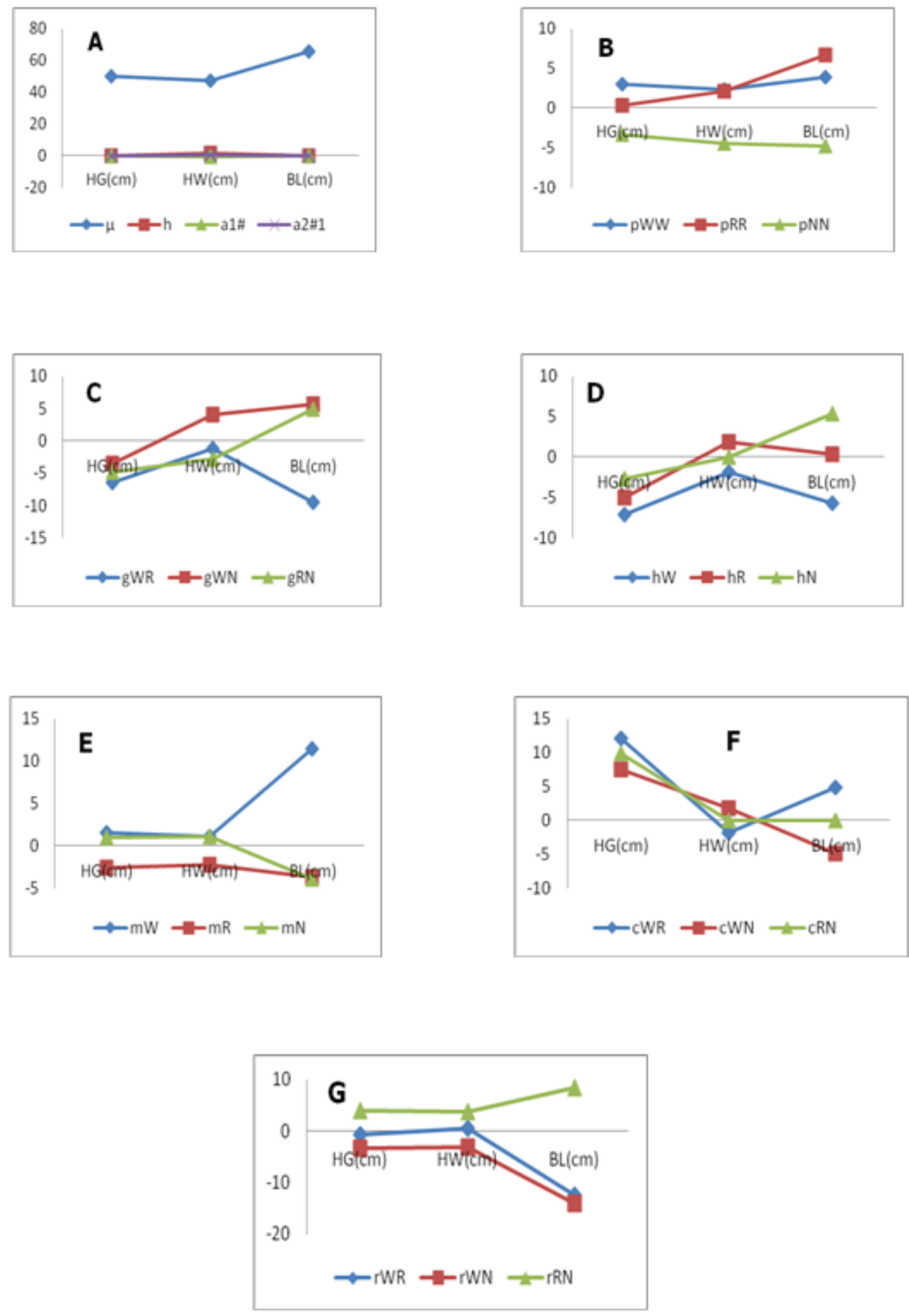

Figure 2. Interactive graph showing the estimates of crossbreeding parameters for conformation traits (heart girt - $H G$, height at withers - HW, \& body length $-B L$ ); $\mu=$ Overall mean, $h(A)=$ mean heterosis, $p=$ direct \& maternal genetic effects, $g=$ general combining ability, $h(D)=$ line heterosis, $m=$ maternal effects, $c=$ specific heterosis, and $r=$ reciprocal effects 
Table 4. Least squares means and standard errors of crossbreeding parameter (Overall mean - $\mu$, mean heterosis - $h$, direct and maternal genetic effects - $p$, general combining ability - $g$, line heterosis - $h$, maternal effects - $m$, specific heterosis - $c$ and reciprocal effects - r) for conformation traits

\begin{tabular}{|c|c|c|c|c|c|c|}
\hline \multirow[b]{2}{*}{ Parameters } & \multicolumn{2}{|c|}{$\mathrm{HG}(\mathrm{cm})$} & \multicolumn{2}{|c|}{$\mathrm{HW}(\mathrm{cm})$} & \multicolumn{2}{|c|}{$\mathrm{BL}(\mathrm{cm})$} \\
\hline & Mean & SEM & Mean & SEM & Mean & SEM \\
\hline$\mu$ & 49.89 & 16.64 & 46.99 & 15.71 & 65.53 & 21.89 \\
\hline $\mathrm{h}$ & 0.07 & 0.03 & 1.43 & 0.58 & -0.13 & 0.05 \\
\hline $\mathrm{a} 1^{\#}$ & -0.04 & 0.03 & -0.715 & 0.29 & 0.07 & 0.025 \\
\hline$a 2^{\# 1}$ & 0.035 & 0.03 & 0.72 & 0.30 & -0.07 & 0.03 \\
\hline $\mathrm{p}_{\mathrm{WW}}$ & $3.03^{\mathrm{a}}$ & 1.06 & $2.38^{\mathrm{a}}$ & 0.82 & 3.90 & 6.84 \\
\hline $\mathrm{p}_{\mathrm{RR}}$ & $0.28^{\mathrm{b}}$ & 1.87 & $2.08^{\mathrm{a}}$ & 2.15 & 6.67 & 4.52 \\
\hline $\mathrm{p}_{\mathrm{NN}}$ & $-3.30^{c}$ & 1.63 & $-4.47^{\mathrm{b}}$ & 2.09 & -4.79 & 1.85 \\
\hline Sig. & $*$ & & $*$ & & ns & \\
\hline $\mathrm{g}_{\mathrm{WR}}$ & $-6.42^{c}$ & 3.12 & -1.20 & 0.39 & $-9.50^{b}$ & 3.43 \\
\hline $\mathrm{g}_{\mathrm{WN}}$ & $-3.55^{\mathrm{a}}$ & 2.44 & 4.02 & 1.24 & $5.59^{\mathrm{a}}$ & 1.66 \\
\hline $\mathrm{g}_{\mathrm{RN}}$ & $-4.82^{b}$ & 1.71 & -2.82 & 0.63 & $4.87^{\mathrm{a}}$ & 2.29 \\
\hline Sig. & $* *$ & & ns & & $*$ & \\
\hline $\mathrm{h}_{\mathrm{W}}$ & $-7.13^{c}$ & 2.91 & -1.85 & 0.62 & $-5.73^{c}$ & 2.34 \\
\hline$h_{R}$ & $-4.97^{\mathrm{b}}$ & 2.03 & 1.86 & 0.62 & $0.39^{\mathrm{b}}$ & 0.16 \\
\hline $\mathrm{h}_{\mathrm{N}}$ & $-2.68^{\mathrm{a}}$ & 1.09 & -0.01 & 0.006 & $5.30^{\mathrm{a}}$ & 2.16 \\
\hline Sig. & $*$ & & ns & & $*$ & \\
\hline $\mathrm{m}_{\mathrm{W}}$ & 1.60 & 0.65 & 1.08 & 0.44 & $11.43^{\mathrm{a}}$ & 4.67 \\
\hline $\mathrm{m}_{\mathrm{R}}$ & -2.57 & 1.05 & -2.23 & 0.91 & $-3.73^{b}$ & 1.52 \\
\hline $\mathrm{m}_{\mathrm{N}}$ & 0.97 & 0.40 & 1.15 & 0.47 & $-3.92^{b}$ & 1.60 \\
\hline Sig. & ns & & ns & & $*$ & \\
\hline $\mathrm{c}_{\mathrm{WR}}$ & $12.14^{\mathrm{a}}$ & 4.05 & -1.85 & 0.62 & 4.93 & 1.64 \\
\hline $\mathrm{c}_{\mathrm{WN}}$ & $7.56^{\mathrm{b}}$ & 2.52 & 1.87 & 0.62 & -4.89 & 1.63 \\
\hline$c_{\mathrm{RN}}$ & $9.85^{\mathrm{a}}$ & 3.28 & 0.01 & 0.006 & 0.02 & 0.007 \\
\hline Sig. & $* *$ & & ns & & ns & \\
\hline$r_{W R}$ & -0.64 & 0.18 & $0.48^{b}$ & 0.14 & $-12.55^{b}$ & 3.62 \\
\hline$r_{W N}$ & -3.35 & 0.97 & $-3.19^{c}$ & 0.92 & $-14.15^{b}$ & 4.08 \\
\hline $\mathrm{r}_{\mathrm{RN}}$ & 3.85 & 1.11 & $3.76^{\mathrm{a}}$ & 1.09 & $8.40^{\mathrm{a}}$ & 2.42 \\
\hline Sig. & ns & & $*$ & & $* *$ & \\
\hline
\end{tabular}

\#and\#1 = purebred and crossbred heterosis respectively, ${ }^{\text {abc }}$ means on the same column within the same parameter but with different superscripts are significantly different. $*=\mathrm{P}>0.05, * *=\mathrm{P}>0.01$.

\section{Discussion}

The observed average heterosis of $-0.27 \mathrm{~kg}, 0.06 \mathrm{~kg}, 2.53 \mathrm{~kg}$ and $1.58 \mathrm{~g} / \mathrm{day}$ for BWB, BWW, BW20 and ADG, respectively, for the growth traits shows there was effective heterosis in the diallel cross, although BWB exhibited negative heterosis. However, the positive average heterosis exhibited by other traits might explain the mostly significant crossbreeding parameters expressed subsequently in the traits. The significant direct and maternal genetic effects on growth traits imply that these traits are influenced significantly by genotypes. The growth traits BWW, BW20 and ADG were influenced more by genotype in breeds RR, RR and NN respectively due to the high mean values they exhibited. Estimates of genetic effects are useful to evaluate pig breeds and to 
develop efficient crossbreeding systems (Hidalgo et al., 2015). Therefore, when selecting purebred lines for crossbred performance, the potential use of dominance, imprinting and breed-specific effects could be considered an alternative to improve the efficiency of crossbreeding and selection.

Hildago et al. (2015) reported non-significant direct genetic effect on weight at all ages for pure bred cross, whereas maternal genetic effects differed significantly for weight at 14, 28 and 154 days of age for purebreds using genomic breeding value accuracy prediction methods. Meanwhile, the crossbred had a significant effect of direct genetic effect on weight at 56,70 and 154 days while for the maternal genetic effect; it differed significantly at birth, 28 and 56 days. Hsu and Johnson (2014) reported highly significant direct maternal effects on 180-d weight (WT180) and longissimus muscle area (LMA) and decreased back fat (BF10) in a Large White - Landrace composite population which favored the Large white breed.

For the significant GCA and its composite; line heterosis, it implies that for the growth traits, BWW, BW20 and ADG, the breeds, NN, WW and RR had a positive line heterosis of $0.74,0.58$ and 0.18 for each breed and GCA values of $0.44,1.69$ and 2.54 for RR, WW and NN breeds respectively. Kurnianto et al. (2010) in a diallel study involving Duroc, Yorkshire and Landrace breeds of pigs estimated GCA for growth traits such as birth weight, average daily gain (ADG), post weaning ADG and body weight at 42 days and found it to be significant and in favour of Duroc breed, due to the highest value reported which implies a significant line heterosis. In a similar vein, Garcia-Casco et al. (2012) in a complete diallel cross scheme with 4 ancient lines of Iberian pigs reported a significant heterotic effect on weight at 420 days of age for the different crosses, while a non-significant heterotic effect for daily growth rate inferred in the first 5 combinations, but the remaining combinations had significant heterosis $(+66 \mathrm{~g} / \mathrm{d})$. Sutha et al. (2015) also reported that in a diallel cross involving Duroc, Yorkshire and Landrace gilts, offspring from Duroc boars were most efficient in feed utilization, and a synthetic three way pig cross was achieved with very high lean weight. They also.reported high heterotic gains in carcasses with less loin fat, a thicker loin muscle, a higher estimated lean yield and a better classification index. These results are in agreement with the findings in this study and by Ibanez-Escriche et al. (2016) in which heterosis effects were relevant for the Retinto and Entrepelado pig breed crosses (approximately $16 \%$ of the trait), which could be valuable for a crossbreeding system involving these lines.

The significant maternal effects with high positive values of $0.27,0.22$ and 1.75 for RR, WW and NN breeds respectively, implies that the traits BWW, BW20 and ADG are influenced more by the dams respectively. Gonzalez-Pena et al. (2015) in a three and four way crossbreeding for swine production reported a significant maternal effect for average daily gain (ADG) backfat (BF), feed efficiency (FE), and carcass lean \% (LEAN) due to semen traits. Silva et al. (1996) estimated the maternal effects on bodyweight at birth, 21, 35, and 77 days in a full diallel crosses involving Duroc, Landrace, Yorkshire and Large White pigs and reported a significant maternal effect at birth, 21 days and 35 days of age. Also, Hsu and Johnson (2014) reported that crossbreeding and selection for growth traits along with litter size selection at 19 to 28 days resulted in responses consistent with the selection applied and the heritability of the trait on maternal effects. Also pig body weights appeared to be positive from weaning to 154days in Yorkshire breed dams, while Duroc dams seemed to perform poorly throughout. The positive influence of Yorkshire gilts on pig size was somewhat 
unexpected in view of the fact that Yorkshire gilts also had the largest crossbred litters. Thus, Yorkshire gilts not only raised slightly larger litters but also weaned heavier pigs and their advantage carried through to 154-day weight.

Also, the significant specific heterosis for BW20 implies that lines for the best specific heterosis are combinations of $\mathrm{W} \times \mathrm{R}$ and $\mathrm{R} \times \mathrm{N}$ with values of $8.41 \mathrm{~kg}$ respectively and the worst combination being $\mathrm{W} \times \mathrm{N}$ with $-1.62 \mathrm{~kg}$. Kurnianto et al. (2010) also reported a significant SCA in favour of Yorkshire $\times$ Landrace breed cross for all the growth traits studied in a diallel cross involving Duroc, Yorkshire and Landrace breeds of pigs.

For the conformation traits, significant direct and maternal effects for $\mathrm{HG}$ and $\mathrm{HW}$ imply that these traits were influenced by the genotype than phenotype. The WW breed exhibited the highest mean value for both traits $(3.03 \mathrm{~kg}$ and $2.38 \mathrm{~kg})$ respectively. With the RR breed being phenotypically characterized by longer body frame than WW and $\mathrm{NN}$ breeds, it was expected that it would have expressed a significantly higher BL. This may be explained by the inherent expression of the trait which might not be only heterotic, but also epistatic. But for the GCA and its composite - line heterosis; there is significant heterotic effect in $\mathrm{HG}$ and $\mathrm{BL}$, with $\mathrm{BL}$ having the highest mean value $(5.59 \mathrm{~cm})$ in $\mathrm{W} \times \mathrm{N}$ cross. In the line heterosis however, $\mathrm{BL}$ trait was exhibited more in RR breed, with the highest mean value of $6.67 \mathrm{~cm}$, showing that the trait might be inherent in the breed naturally and expressed epistatically instead of in heterosis. Meanwhile, HG trait exhibited negative mean values for both GCA and line heterosis, even though significantly influenced. This might imply that the traits were negatively influenced in the three breeds analyzed. The maternal effects are also significant only in BL trait, while HG and HW were not. This is more exhibited in the WW breed, as shown in its mean value of $11.30 \mathrm{~cm}$, which implies that that the dams of this breed enhances the trait in swine. The specific heterosis also showed that only HG trait was significantly influenced while $\mathrm{HW}$ and $\mathrm{BL}$ were not with the $\mathrm{W} \times \mathrm{R}$ combination exhibiting the highest value $(12.14 \mathrm{~cm})$ while $\mathrm{W} \times \mathrm{N}$ was the least. This implies that $\mathrm{HG}$ trait is more expressed in the $\mathrm{W} \times \mathrm{R}$ combination. Whereas for the reciprocal effect, $\mathrm{HW}$ and BL traits were significantly influenced, while HG was not. The combination of $\mathrm{R} \times \mathrm{N}$ was consistently highest in mean values for both $\mathrm{HW}$ and $\mathrm{BL}$ traits, showing that the reciprocal cross will be influenced in the same way as the main cross.

\section{Conclusion}

Effective combination of local breeds of animals such as Nigerian indigenous breeds in crossbreeding programs to improve growth and reproductive traits has been advocated, as shown by the advantage of Chinese breeds used in production due to its high prolificacy (Rothschild, 1996). The Nigerian indigenous pigs in this study have shown its ability to enhance the specific heterosis with the Landrace breed in improving bodyweight at 20 weeks, which could have major underlying advantage in commercial swine production. This study which is aimed to understand the genetic underpinnings of the breeds as well as the best combination to enhance growth and conformation traits, may also enhance the adaptability of the crossbreds in the harsh tropical environment where the exotic breeds are not used to. 


\section{REFERENCES}

[1] Balaguer, C. M. (2014): Genetic analyses of growth, carcass and meat quality traits in maternal lines of rabbits and their diallel cross/análisis genético de caracteres de crecimiento. PhD, Universitat Politecnica De Valencia.

[2] Duro, S., Okoro, V., Ogundu, U., Udedibie, A., Okoro, C., Ukwu, H.,Ibe, S. N. (2015): Effect of genotype, sex and parity on growth traits of diallel crossed Nigerian indigenous and exotic pigs. - Nigerian Journal of Animal Production 42: 32-40.

[3] Eisen, E. J., Horstgenschwark, G., Saxton, A. M., Bandy, T. R. (1983): Genetic Interpretation and Analysis of Diallel Crosses with Animals. - Theoretical and Applied Genetics 65: 17-23.

[4] Fernandez, A., Rodriguez, M. C., Rodriganez, J., Silio, L.,Toro, M. A. (2002): Use of Bayesian analysis of growth functions to estimate crossbreeding parameters in Iberian pigs. - Livestock Production Science 73: 213-223.

[5] Garcia-Casco, J. M., Fernandez, A., Rodriguez, M. C.,Silio, L. (2012): Heterosis for litter size and growth in crosses of four strains of Iberian pig. - Livestock Science 147: 1-8.

[6] González-Peña, D., Knox, R. V., MacNeil, M. D., Rodriguez-Zas, S. L. (2015). Genetic gain and economic values of selection strategies including semen traits in three- and fourway crossbreeding systems for swine production. - Journal of Animal Science 93:879891.

[7] Harvey, W. (1960): Least-squares analysis of data with unequal subclass numbers. - In: Ars, U. (ed.). Maryland: USDA.

[8] Hidalgo, A.M., Bastiaansen, J.W., Lopes, M.S., Harlizius, B., Groenen, M.A., de Koning, D.-J. (2015) Accuracy of predicted genomic breeding values in purebred and crossbred pigs. G3: Genes|Genomes|Genetics 5: 1575-1583.

[9] Hsu, W. L., Johnson, R. K. (2015). Analysis of 28 generations of selection for reproduction, growth, and carcass traits in swine. - Journal of Animal Science 92:48064822.

[10] Ibanez-Escriche, N., Varona, L., Magallon, E., Noguera, J. L. (2014): Crossbreeding effects on pig growth and carcass traits from two Iberian strains. - Animal 8: 1569-1576.

[11] Ibáñez-Escriche, N., Magallón, E., Gonzalez, E., Tejeda, J. F., Noguera, J. L. (2016). Genetic parameters and crossbreeding effects of fat deposition and fatty acid profiles in Iberian pig lines. - Journal of Animal Science 94:28-37.

[12] Jakubec, V., Komender, P., Nitter, G., Fewson, D.,Soukupova, Z. (1987): Crossbreeding in Farm-Animals .1. Analysis of Complete Diallel Experiments by Means of 3 Models with Application to Poultry. - Journal of Animal Breeding and Genetics-Zeitschrift Fur Tierzuchtung Und Zuchtungsbiologie 104: 283-294.

[13] Kurnianto, E., Arifin, M.,Nugroho, P. (2010): Partial diallel cross analysis among three breeds of pigs for productive and reproductive traits. - Jurnal Sains dan Teknologi Indonesia 12: 21-24.

[14] Okoro, V. (2012): Evaluation of Reciprocal, Maternal, Sex-linked and Heterotic Effects on Growth and Reproductive Traits in Pigs. PhD, Michael Okpara University of Agriculture, Umudike.

[15] Rothschild, M. (1996): Genetics and reproduction in the pig. - Animal Reproduction Science 42: 143-151.

[16] SAS Institute. 2010. SAS/STAT 9.3 user's guide survey data analysis. SAS Institute. $8640 \mathrm{p}$.

[17] Silva, M. D. E., Sancevero, A. B., Alves, R. G. D., Deoliveira, A. I. G., Lopes, P. S.,Torres, R. a. D. (1996): Effect of type of cross on litter size and litter weight of purebred and crossbred swine. - Brazilian Journal of Genetics 19: 249-258.

[18] Sutha, M., Gawdaman, G., Robinson, J., Abraham, J., Thirumurugan, K. (2015): Influence of age on the carcass characteristics of three way synthetic pigs raised under swill feed regime. - Indian Journal of Animal Research 49 (1): 114-117. 